\title{
GRAMÁTICA Y COGNICIÓN: EL DATIVO DE DIRECCIÓN.
}

\author{
Jesús Llopis GANGA \\ (Universidad de Alicante)
}

\begin{abstract}
RESUMEN
Our aim in this essay is to analyce from a cognitive point of view the possibility, wich verbs of direction present of identifying terms of movement both an a person and a place; that is to say, the question of the relationship between indirect and directional objects when they occur as objects of a verb of movement. A [+human]-featured element, i.e., a person, can be taken as the basis or benchmark after which the movement or path expressed by the verb may be positioned, since verbs of direction may well conceptualize their terms of movement both as a person or a place. Even though the element taken as benchmark is a person, it will be conceptulized with verbs of direction as a place - place occupied by the person itself - So, in directive structures the person functions as a directional object. Thus, we consider that indirec and directional objects do not behave as two separate and distinct forms functionally, but rather they should be understood as two different notions of one and the same function: that of term of direction.
\end{abstract}

\section{La Gramática Cognitiva como principio explicativo del mecanismo lingüístico}

En este trabajo hemos partido de ciertos presupuestos metodológicos que han condicionado nuestro acercamiento al objeto de investigación, puesto que se enmarcan dentro de una perspectiva cognitiva del lenguaje ${ }^{1}$. El punto de vista cognitivo constituye una de las perspectivas básicas desde la que realizar un estudio del uso del lenguaje; por ello, consideramos la Gramática Cognitiva

1 Esta breve exposición de los aspectos metodológicos esenciales de esta perspectiva linguística son semejantes a los que expone J. L. Cifuentes en su obra Gramática Cognitiva. Fundamentos críticos (1994), a la que remitimos para una mayor profundización en estos aspectos. 
como una perspectiva desde la que realizar un estudio del uso de la lengua, complementaria, en efecto, con otras perspectivas de análisis no coincidentes (por lo que estudiaremos el complemento indirecto no sólo desde una perspectiva semántica, sino también con otras perspectivas complementarias: sintáctica, referencial, etc.). Un presupuesto general del que partimos es el de que el lenguaje posee una naturaleza simbólica, y esta concepción afecta también a la gramática: las estructuras morfológicas y sintácticas son inherentemente simbólicas, pues la gramática es simplemente la estructuración y simbolización del contenido semántico. Dentro de este campo, el principio de iconicidad lingüística -que presupone que ciertas estructuras lingüísticas de una lengua son eminentemente icónicas al reflejar en su propia disposición el contenido que poseen y denotan- manifestaría este simbolismo del lenguaje.

Otro presupuesto general del que partimos es que el lenguaje es parte integral de la cognición humana. El lenguaje utiliza nuestro aparato cognitivo general: organizamos nuestro conocimiento por medio de estructuras llamadas modelos cognitivos idealizados (una consideración prototípica de la organización categorial va a ser constante en nuestro trabajo, de igual manera, cuando adoptemos una perspectiva semántica no va a ser una semántica exclusivamente léxica o inmanente).

Pensamos que las unidades semánticas son caracterizadas según dominios cognitivos, y cualquier concepto o sistema de conocimiento puede funcionar como un dominio para este propósito (el dominio cognitivo que sustenta nuestro trabajo es el de la transferencia: dominio de llegada y dominio de partida). Partimos también de la idea de que las expresiones lingüísticas pertenecen a situaciones conceptualizadas o «escenas» (Langacker, 1987:1 16); así dos experiencias pueden resultar cualitativamente distintas a pesar de ser provocadas por los mismos estímulos. Es decir, la misma situación puede ser descrita por una variedad de expresiones distintas semánticamente que incorporan diferentes maneras de construirlas o estructurarlas - veáse en la alternancia preposicional a/de del tipo: huía del ladrón/ huía al ladrón, arrancó la rama del árbol/le arrancó la rama al árbol; el problema de la conversión lugar-objeto, o los casos de iconicidad que presenta el clítico correferencial-.

Creemos necesario realizar un estudio gramatical de base semántica, ya que la gramática es y debe ser semántica en la medida que tiene que estudiar y describir el lado semántico de la lengua; con ello, estamos focalizando que las lenguas son esencialmente estructuraciones semánticas del mundo extralingüístico (nuestra delimitación funcional del dativo de dirección lo pondrá de manifiesto). Pero el conocimiento semántico deriva del conocimiento cultural, por lo que mantenemos el carácter social y cultural de los signos, ya que la significación léxica exige tanto del núcleo sémico como de la base contextual. Luego, es obvio que una perspectiva semántica, de base pragmática, será necesaria para el estudio de cualquier unidad lingüística. 
Y por último, aplicamos la teoría de prototipos a la categorización lingüística; con prototipo sólo queremos decir que hay diferencias entre los miembros de una categoría metodológica. La solución para explicar la agrupación de entidades diferentes en una misma categoría se produce por medio de los «parecidos familiares»: la teoría del parecido familiar es un modelo que sólo prevé, pero que no exige, que los miembros de una misma categoría puedan no tener ningún rasgo en común. De este modo, se puede hablar de grados de prototipicidad en el seno de una categoría (Véase la categorización prototípica que proponemos para el clítico correferencialde dativo).

\section{El dativo de dirección}

Al clílico de dativo le / les, que aparece con los verbos direccionales, que sirve para aludir a la persona que se toma como término o sentido del movimiento, y que concurre con un sintagma preposicional introducido por $a$, se le conoce usualmente con el nombre de dativo de dirección ${ }^{2}$. Sin embargo, a pesar de lo adecuada que parece esta nomenclatura para describir el problema estudiado, su caracterización no nos parece ajustada, pues efectúan un doble análisis que consideramos cquivocado- de elementos que realizan una misma función sintáctica y semántica - término del movimiento- mientras que lo único que varía es su forma (pronombre personal átono vs. sintagma preposicional con $a$ ). Además, realizando un doble análisis no se podrían explicar las estructuras donde aparece el clítico correferencial, es decir, estructuras donde aparece el sintagma preposicional, pero donde también es exigido el pronombre dativo átono le/les (El dentista le arrancó un diente a Pedro).

Luego, el dativo de dirección semánticamente no es propiamente un dativo, sino un verdadero complemento de lugar en el que la base es una persona; vemos, pues, que su diferencia no es sintáctica, sino de conceptualización semántica del esquema verbal.

Ahora bien, hemos de señalar que recogemos la nomenclatura de «dativo de dirección» por considerar que describe muy bien la identidad funcional, desde un punto de vista sintáctico-semántico, entre el complemento indirecto y el complemento direccional con los verbos de dirección. Sin embargo, con dativo de dirección denominamos a los considerados «complementos indirectos» que aparecen con los verbos de dirección, es decir, a los complementos direccionales con el rasgo [+ humano], puesto que semánticamente no son complementos indirectos sino complementos direccionales.

2 Preferentemente la tradición gramatical acoje bajo la denominación de dativo de dirección tanto al clítico de dativo vinculado a verbos direccionales como a verbos posicionales (le puso el sombrero). Nuestro estudio lo hemos centrado exclusivamente en el dativo de direción que aparece con verbos direccionales. 


\section{La estructura de «doble objeto» y los verbos de dirección}

Resultaría relevante observar cómo, en numerosas lenguas no emparentadas, existe cierta similitud entre el complemento direccional y el indirecto; por lo tanto, parece ser que nos podríamos encontrar ante un problema de similitud en la conceptualización. Es por ello que pueda resultar interesante comparar dos oraciones del tipo Envié una caja de alimentos a Maria / a México, en donde el rasgo [ + animado] del sintagma preposicional introducido por a nos puede llevar a cuestionarnos si tiene un sentido local o no, circunstancia que no se nos presenta en la segunda posibilidad.

A este respecto J.Lyons (1968: 314-315) se pregunta si el sentido direccional de $a$ en Fuía Valencia no está relacionado con el $a$ del objeto indirecto en Di el libro a Juan. Pero cree que todavía no se ha hecho un estudio sincrónico lo suficientemente profundo como para poder decir con exactitud la coincidencia que existe entre las funciones más claramente «locales» y las funciones más claramente «nominales» en las correspondientes preposiciones de una lengua particular. Pero a pesar de la falta de estudios sobre esta cuestión, considera necesario su estudio por parte de la Lingüística General:

«...ciertos puntos de coincidencia a lo largo de lenguas sin relación genética mutua son tan sorprendentes que exigen una explicación en teoría sintáctica general. Uno de tales puntos de coincidencia [...] consiste en la similitud entre el objeto direccional y el objeto indirecto en muchas lenguas (Cfr.Fui a Londres y Di el libro a Juan. Nótese que envié el libro a Juan se podría dudar sobre si Juan es objeto direccional u objeto indirecto.»

(Lyons, 1968: 314-315)

Los ejemplos que comenta Lyons son los que él denomina de «tres lugares» (p.e. dar o poner), aquellos que se combinan con un sujeto, un objeto directo y un objeto indirecto (o locativo direccional): Juan dio el libro a Guillermo (donde el libro es el objeto directo y a Guillermo el objeto indirecto) o bien Juan puso el libro en la mesa (donde el libro es el objeto directo y en la mesa un locativo $)^{3}$. También menciona el autor otras estructuras en las que puede aparecer esta coincidencia, y que podríamos denominar de «dos lugares»: Juan ha ido a su casa. Según él, el que una construcción locativa dinámica de «dos» o de «tres lugares» se utilice en un caso determinado depende de si la persona o el objeto que está implicado en la locomoción es «agentivo» o no ${ }^{4}$. Así, explica

3 Es mucha la confusión añadida que hay sobre este tema, pues muchas veces no se usan como ejemplos verbos direccionales ni locales (dar), y en algunas ocasiones, aun siendo locales, no son direccionales (poner). Aspecto este último muy interesante, pues la conversión objeto/lugar no sólo se da con los verbos direccionales, sino también con los posicionales estativos.

4 Nosotros lo explicamos mediante las funciones de figura y base. 
que el libro ha ido a Londres, aunque no es agramatical, es menos normal que Juan ha ido a Londres, y que puede implicar la «recategorización» de el libro como «animado»; Guillermo llevó a Juan a San Francisco en contraste con Juan fue a San Francisco, marca a Guillermo como «agentivo» y a Juan como «no agentivo».

Finalmente afirma que en muchas ocasiones es imposible distinguir el complemento indirecto del direccional por su gran parecido, e incluso deja vislumbrar su misma identidad funcional, así como las fronteras poco claras entre el dativo de dirección y el dativo posesivo:

«...puede observarse que las posesivas y las locativas no siempre se distinguen con claridad en construcciones de «tres lugares», sería imposible, y tal vez innecesario, decir si tráigame el libro es «posesivo» o «locativo», en otras palabras, si me es el objeto indirecto o direccional: hemos llamado la atención sobre el hecho de que el mismo caso o la misma preposición en muchas lenguas se emplean indistintamente para el «complemento indirecto» y para el «movimiento a». Una vez más, notamos la similitud ( y quizás la identidad esencial) de las locativas y las posesivas.».

(Lyons, 1968: 412)

Esta relación que mantiene la preposición a con el complemento indirecto y con el complemento direccional puede ser semejante, tal vez, a la que existe entre las oraciones sustantivas de complemento indirecto y las subordinadas adverbiales de finalidad, pues ambas van introducidas por la preposición $a$, determinan el destino del proceso y funcionan como meta.

Esta similitud entre el complemento direccional y el indirecto puede estar motivado por el similar valor significativo que caracteriza a ambos complementos; el complemento indirecto con su noción de 'afección' designa a aquellas entidades que resultan «afectadas» por la acción verbal, fundamentalmente personas; el complemento direccional con su valor de 'meta' o 'destino' indica el término o lugar que se encuentra «afectado» por el movimiento expresado por el verbo - en tanto que es el dominio de llegada o el de partida-. Por lo tanto, el considerarlo como uno u otro complemento sólo dependerá de las restricciones semánticas que imponga el verbo, que sea local o no.

\section{Análisis sintáctico-semántico de los verbos de dirección}

Las características sintáctico-semánticas propias de las construcciones directivas, que son las que permiten la combinación tanto con un lugar como con una persona, muestran dos claras propiedades formales:

1) Parecen formar dos paradigmas en lo que respecta a la partícula que introduce el segundo objeto, según lleven a (Entregó el lápiz a su compañera) la 
preposición canónica de los complementos indirectos, o tomen -en muchos casos en alternancia con $a-$ otras preposiciones que añaden precisiones al significado locativo-final de $a$. Así de sustituye la idea de localidad-final de $a$ por la de localidad-inicial (Arrancó las páginas del libro). Pero hay que tener mucho cuidado y diferenciar el significado direccional de $A$, con verbos de desplazamiento, del significado de relación de contigüedad que puede darse con verbos locales estativos (pegar la estampilla al documento).

Violeta Demonte (1994: 58) propone mezclar como uno de los pocos verbos que permiten combinarse, al menos, con tres preposiciones: mezcló la harina af en/con los huevos, según ella, porque las materias del objeto de movimicnto y el destino del mismo permiten varios resultados, a diferencia de lo que sucede, por ejemplo, con el acto de mover un objeto material hacia otro objeto material: acercó la silla a $/$ en $^{*}$ con la mesa. En este último caso no es posible ni una locación dispersa ni un contacto total entre el Tema y la Meta. Consideramos que el ejemplo que propone de mezclar con a resulta un poco forzado (?mezcló la harina a los huevos). Pero, quizás, de estos ejemplos lo más destacable sea que se hace una distinta conceptualización de un mismo hecho, es decir, nos podemos encontrar una conceptualización local y otra no local de un mismo hecho.

(1) a) Mezcló la harina en los huevos (local).

b) Mezcló la harina con los huevos (no local).

(2) a) Le pellizcó la cara (no local).

b) Le pellizcó en la cara (local).

(2 bis) a) Subió las escaleras.

b) Subió por las escaleras.

2) Su segundo objeto puede representarse por medio de un clítico dativo, y esto puede afectar tanto a verbos direccionales como posicionales.

(3) a) Juan entregó el lápiz a su compañera.

b) Juan le entregó el lápiz a su compañera.

Este clítico suele aparecer con el objeto preposicional al que representa, ya que el español es una lengua que admite los llamados «objetos doblados» o la reduplicación mediante clíticos (propiedad ésta no compartida con otras lenguas que también poseen pronombres átonos o clíticos). Sin embargo, el funcionamiento de este clítico correferencial no es el mismo con todos los verbos de movimiento.

Desde un punto de vista semántico, los verbos direccionales hacen hincapié en la dirección del movimiento, así su definición semántica exigirá una referencia al punto de partida o al de llegada, o a ambos. Por tanto, este tipo de 
complementos aparecerá en la caracterización significativa de tales verbos, mientras que no ocurre con otros verbos transitivos (comer, hacer, leer) que no exigen una especificación de este tipo.

«La noción de orientación se analiza, pues, como un cierto estado resultativo de un movimiento o de un desplazamiento, real o virtual. Orientar un objeto es disponerlo en una dirección determinada [...]. Todo desplazamiento puede ser reducible a un vector geométrico del que se puede definir la magnitud, la dirección y el sentido. La magnitud del vector $A B$ es la distancia recorrida entre A y B; el sentido del vector define una orientación secundaria según sea considerado positivamente como yendo de $\mathrm{A}$ hacia $\mathrm{B}$, o negativamente como yendo de B hacia A. La categoría semántica del desplazamiento articula, pues, una oposición entre el punto de partida y el de llegada, resultante de la doble orientación vectorial según la dirección y el sentido ».

(Cifuentes, 1988-89: 162)

De esta forma, el desplazamiento puede ser señalado tanto por un verbo tradicionalmente transitivo (en combinación con lo que se ha llamado un complemento directo) como por un intransitivo (Cifuentes, 1988-89: 161-162). Si es intransitivo no puede aplicarse más que al sujeto como figura; si es transitivo, el desplazamiento puede referirse tanto al sujeto como al objeto, o a los dos conjuntamente; un verbo intransitivo puede incluso especificar un movimiento del objeto sin que se acompañe de desplazamiento.

\section{Las preposiciones $A$ y $D E$ con los verbos de dirección}

Cuando el origen está constituido por una persona [+animado] prefiere o selecciona, por lo general, la preposición $a$. La aparición con $a$ de un verbo que determina el origen y que va delante de un S.N. [-animado] implica, normalmente relación de 'pertenencia' o 'posesión inalienable' entre el complemento directo y el indirecto.

(4) Arrancar una rama al árbol/del árbol.

E. Roegiest (1983) estudia la relación existente entre la preposición a y de con los verbos de dirección, y considera que el Dativo (beneficiario de la acción) plantea el problema de la contrastividad o complementariedad con la Meta y/o Locativo. Así, Dativo y Locativo, si pertenecen al esquema casual del verbo son complementarios, pues varios factores confirman que hay, al menos, paralelismo entre el Dativo (término de la atribución) y la Meta (término de la dirección). Los dos argumentos, Dativo y Meta/Locativo, se caracterizan por una cohesión fuerte con el predicado, determinan la localización del objeto (directo), y tienen un circunstante (argumento de cohesión débil, fuera del esquema casual del verbo) emparentado, el Benefactivo (Compró el tabaco a la 
estanquera para su padre) y el Locativo exterior (Jugar con los niños en el jardín). De este modo, afirma que muchas veces sólo el contexto permite distinguir entre atribución y dirección, es decir, entre Dativo y Locativo.

Esta analogía sugiere que ambos casos son complementarios, lo que confirman las proposiciones con enviar, mandar, llevar, traer, etc., es decir, con verbos direccionales, en que la presencia simultánea de un posible objeto indirecto animado y un complemento de dirección resulta difícilmente aceptar ble.

(5) *? Juan envió un libro a María a Madrid.

Esta complementaridad parece excluir la coordinación; lo cual, es lógico, pues no puede haber dos términos de llegada.

(6) ? Envió la carta a Freud y a Viena.

Por consiguiente, parece ser que la complementariedad entre el Dativo y el término del movimiento directivo no parece corresponder a la oposición [+ animado] vs. [- animado], como se ha considerado siempre, sino que está condicionada por la naturaleza de la relación entre los argumentos correspondientes en la frase.

E. Rogiest opina que en español, contrariamente al inglés que generaliza el uso de from, así como en los demás idiomas románicos, de entra en competencia con a que se prefiere frecuentemente. A primera vista, la conmutabilidad de ambas preposiciones está condicionada por la oposición [+animado] vs. [-animado], es decir, un S.N. [-animado] que se refiera al origen de un movimiento no admitiría sino de, pero esta oposición no resulta pertinente, pues también puede aparecer cuando el determinante del origen del proceso es una persona. La aparición de a delante de un S.N. [-animado] está ligada a una relación de pertenencia entre objeto directo y objeto indirecto, y es por ello que, en estos casos, el S.P. de origen permita tanto una interpretación espacial como una interpretación posesiva, no encontrándonos ante unos límites claramente definidos.

(7) a) El jardinero arrancó la rama del árbol

b) El jardinero le arrancó una rama al árbol.

En este ejemplo existe una relación 'parte-todo' entre el complemento directo y el posible indirecto, es decir, la rama es una de las partes constitutivas del árbol, concibiéndose, por tanto, como una 'posesión inalienable'. Lo mismo sucedería con Juan le sacó el hueso al melocotón, en el que el hueso es una de las partes constitutivas del melocotón por lo que se caracteriza como una 'posesión inalienable', es decir, A posee a B de tal forma que B (objeto poseído) no existiría sin la presencia de A, y por tanto, si B (objeto poseído) está presente en el discurso, A (el poseedor) debe estarlo también obligatoriamente. Además, 
parece que, si no aparece el clítico le, no aparece la preposición $a$, sino de, luego parece que la preposición a implica cierta personificación.

(8) a) Juan le sacó el hueso al melocotón.

b) Juan sacó el hueso de la olla.

La posibilidad de una doble interpretación en algunos contextos explica por qué ambas preposiciones pueden entrar en competencia. Por otra parte, un nombre que designe sitio o lugar selecciona lógicamente de, mientras que un nombre [+animado] prefiere, por lo general, la preposición $a$.

(9) a) Quitaron la guarnición de aquel sitio (-animado).

b) Quitaron la guarnición a la caballería (+animado).

De este modo, proponemos comparar la imposibilidad de la presencia de la preposición $a$ cuando no se da la posesión entre complemento directo e indirecto.

(10) a)El niño le extrajo una torta del cesto a su madre.

b) *El niño le extrajo una torta al cesto.

La preposición $a$ introducirá fácilmente un S.N [-animado] y [-concreto] con el que establece una relación de pertenencia abstracta: quitar algo de la cabeza, pero quitar algo a lo escrito; restar una suma del total, pero restar importancia a sus palabras. Pero aparte del papel desempeñado por el sintagma nominal, el verbo condiciona el uso de tal preposición; pues no todos los verbos de dirección se comportan del mismo modo.

Si la diferencia de construcción entre $a$ y de no depende de la oposición [+animado] vs. [-inanimado] entonces ¿Por qué está motivada? Esta diferencia tiene que ver más bien con el grado de agentividad del predicado (Roegiest, 1983: 37-39).

«Los verbos que sólo admiten de como recibir y obtener no son agentivos. En otros términos, $a$ aparecerá solamente si el sujeto del verbo es a la vez Agente y Meta de la acción. El sujeto de un verbo no agentivo, siendo la Meta de la acción, implica un argumento marcado como Origen, mientras que la presencia de un Agente permitiría al Origen que sea interpretado como término de la acción agentiva: el Agente, instigador del proceso, se opone a un Dativo inactivo, lugar o sitio del proceso".

(Roegiest, 1983: 38)

De este modo, el sintagma preposicional reaparece marcado como origen en la medida en que se acentúa la dirección o, en la medida en que el sujeto gramatical se caracteriza por una agentividad menor. Por lo tanto, se observa que de reaparece con mayor frecuencia cuando el verbo, a pesar de su carácter 
agentivo - patente, por ejemplo, por su conversión en imperativo- implica una acción cuyo agente es co-referencial con el origen del proceso descrito. Creemos que esto explicaría los casos en que alterna la preposición a y de en la determinación del origen del proceso cuando la entidad que funciona como Origen posee el rasgo [+animado], como ocurre con el verbo huir.

(11) El ladrón huía de/a los policías.

El proceso que describe este ejemplo podría parafrasearse por A huye de B, y esto implica que $\mathrm{B}$ persigue a $\mathrm{A}$, en que $\mathrm{B}$ tiene la iniciativa del proceso, es decir, es el agente.

«En el caso de los verbos agentivos, en que de puede conmutar con a (huir, arrancar), suponemos la presencia de dos predicados subyacentes: uno causativo y otro directivo. El Origen sube hasta el término (Meta) del proceso causativo, a menos que la dirección sea acentuada [...] Así se comprende que la presencia de una relación de pertenencia, en vez de una relación concreta de de localización, favorecerá la subida, mientras que la dirección del proceso se impone más fácilmente cuando el sujeto del proceso presenta una agentividad menos fuerte, como en el caso de aceptar»,

(Roegiest, 1983: 39)

Así, el término del proceso agentivo (Dativo/Meta) no va a permitir tan fácilmente la complementariedad o contrastividad con un sintagma preposicional con de (origen del movimiento) cuando el argumento aludido desempeñe un papel más activo en el proceso que el sujeto gramatical, pues éste se caracteriza por un grado menor de agentividad que el sujeto de arrancar.

(12) El jardinero le arrancó una rama al árbol.

Creemos que el proceso descrito en el ejemplo anterior podría parafrasearse de forma lógica así: $\mathrm{A}$ arranca $\mathrm{X}$ a $\mathrm{B} \rightarrow \mathrm{A}$ hace (arrancando) que $\mathrm{X}$ no es de $\mathrm{B}$, o sea, A CAUSA [neg. (X C B)].

La aparición de la preposición a se debe a lo mejor a la presencia del sólo rasgo [tagentivo], apoyada por la relación de posesión, pues ya conocemos el uso frecuente del objeto indirecto en vez de un complemento adnominal, si este mantiene con el objeto directo una relación de posesión inalienable.

(13) No me han aceptado el artículo en el períodico.

\section{Complemento indirecto y complemento preposicional o suplemento}

La Gramática de la Academia (1994:292) en cuanto a la posible confusión entre el objeto indirecto y el objeto preposicional (Complemento Suplemento 
para Alarcos y Martínez García), afirma que la diferenciación entre ambos es fácil, pues el objeto indirecto se sustituye por el pronombre dativo átono (le, les) mientras que el objeto preposicional se sustituiría por una unidad tónica, un sintagma preposicional introducido por $a$.

(14) a) A esa chica siempre le huele el pelo a fritura.
(C. Indirecto).
(C. Preposicional).

b) Le huele siempre el pelo a fritura.

c) Le huelc a eso.

Quizás el cjemplo que propone no sea el más adecuado para ejemplificar esto, pues a fritura parece más bien un complemento circunstancial de modo.

Crcemos que el criterio adoptado por la Academia para diferenciar las funciones complemento indirecto y complemento preposicional o suplemento, basándose exclusivamente en la oposición de la pronominalización por el dativo átono lefles, no explicaría los usos de este pronombre como elemento correferencial a un sintagma preposicional introducido por a con el rasgo [humano].

(15) Le arrancó el pomo a la puerta.

También hace referencia a la relación existente entre el objeto indirecto y el «adyacente circunstancial» (Complemento circunstancial), afirmando que no es difícil discernir entre objeto indirecto y el adyacente circunstancial con $a$, pues la situación impide toda ambigüedad.

\section{(16) a) Puso dos cerraduras a la puerta (objeto indirecto) \\ b) Puso dos macetas a la puerta (adyacente de lugar)}

Luego, realiza un doble análisis atendiendo exclusivamente a la realidad extralingüística, proponiendo de este modo dos funciones sintácticas distintas de un mismo elemento; sin embargo, en lo único que se diferencian es en el significado denotativo de sus complementos directos (incluso tienen ambos el rasgo [-humano] ).

Atendiendo a la referencia extralingüística de una situación dada, intenta encontrar en estas oraciones sentidos concretos de lo designado por el objeto indirecto. Así, como cerradura es una parte integrante de la puerta, considera a ésta como una entidad que se ve más afectada por la designación del proceso verbal ( poner dos cerraduras), debido fundamentalmente a la mayor implicación que hay entre cerradura y puerta que entre maceta y puerta, donde, desde un punto de vista referencial, las macetas no serían parte constituyente de la puerta, es decir, macetas no implicaría a puerta, mientras que cerradura sí que implica a puerta. 
En nuestra opinión, el único motivo que les induce a pensar en dos funciones distintas y proponer un doble análisis es el de la solidaridad léxica (cfr. Coseriu 1977: 148) que existe entre cerraduras y puerta. Es precisamente la implicación de puerta por parte de cerraduras la que motiva que consideren a puerta como una entidad más afectada por el proceso designado mediante el verbo en el primer caso que en el segundo. Y este supuesto mayor grado de «afección» provocado por la implicación de la solidaridad léxica parece estar más acorde con la caracterización del complemento indirecto como «ente afectado por el proceso verbal» - puesto que caracterizamos el contenido de la función complemento indirecto con el rasgo 'tafección'- que con la del complemento circunstancial (optatividad, circunstancia, etc.).

Luego, nos parece incorrecto este doble análisis, pues la diferenciación sólo es posible atendiendo a la realidad extralingüística. En realidad, nos encontramos ante una misma función sintáctica y semántica, ante una misma estructura verbal, e incluso, en este caso concreto, ante un mismo lexema que hace referencia a la misma realidad extralingüística.

Como vemos, en muchos de los ejemplos que los distintos autores proponen para ejemplificar la relación entre el complemento indirecto y el complemento preposicional aparecen verbos «posicionales». Nosotros no vamos a considerar los verbos «posicionales», pues su funcionamiento es distinto al de los verbos de movimiento; los «posicionales» no suelen admitir las preposiciones de movimiento ( $a$, de, desde, hacia, hasta y para).
(17) a) Colocó la maceta en la puerta
b) Colocó la maceta a la puerta
c) *Colocó la maceta hacia la puerta
d) *Colocó la maceta hacia la puerta
e) ?Colocó la maceta desde la puerta

Fuera ya de las propuestas academicistas de carácter más normativo, encontramos también algunas alusiones a la relación entre el complemento indirecto y el complemento preposicional o suplemento en varios estudios de carácter más descriptivo y explicativo.

$M^{a}$ V. Vázquez (1989: 145) reconoce que en los esquemas del tipo SUJPRED.- C.DIR.- C.IND., el argumento que funciona como complemento indirecto presenta, al menos con algunos verbos, ciertas peculiaridades que plantean el problema de los límites entre esta función sintáctica y otras como el complemento adverbial o suplemento y el circunstancial.

Para esta autora, la posibilidad de pronominalización parece estar restringida a los casos en que el tercer argumento (segundo en la estructura intransitiva) posee el rasgo [+ animado], pues cuando este constituyente es [-animado] pronominaliza en adverbial de lugar: 
(18) Juan se acercó a ella/se le acercó

Término movimiento

[+ humano] ...Pronombre átono (le, les)

(19) Juan se acercó a la pared/ allí

Término de movimiento.

[ - humano] ...Sintagma adverbial (allí)

No creemos que la oposición del rasgo [+ humano] o [- humano] se pueda utilizar para diferenciar el complemento indirecto del complemento preposicional o suplemento, ni identificar tan taxativamente el rasgo [+ humano] o [- humano] con la sustitución por le/les o por un adverbio respectivamente, pues en muchos ejemplos no encontraríamos tal identificación.

(20) Juan le dió cuerda al reloj [-Humano]

(21) La grúa le arrancó el parachoques al coche [-Humano]

Pero si en un momento $\mathrm{M}^{\mathrm{a}}$. V. Vázquez defiende este doble análisis, al considerarlas como estructuras sintácticas diferentes, en otro momento viene a reconocer que en muchos casos ambas funciones (complemento indirecto y complemento suplemento) pueden llegar a coincidir. Es por ello que toma una postura ambigua ante este problema:

«Por otro lado, es evidente que incluso en los casos en que podemos considerar que el elemento en cuestión es un complemento indirecto, está presente un cierto valor locativo, inherente a la clase semántica de los verbos de movimiento. En estas circunstancias el constituyente en función de complemento indirecto de alguna forma tiene el papel de índice espacial, de manera que por una parte «llena» el argumento locativo de la valencia de este tipo de verbos, y por otra añade el rasgo de contenido específico de los complementos indirectos».

(Vázquez, 1989: 205)

Para ella, estos elementos funcionan como índices locativos, en concreto, expresan el término del movimiento, es decir, la entidad humana a que se refiere el complemento indirecto se concibe, entonces, como referencia espacial en cuya órbita se situaba, antes del movimiento, la otra entidad que aparece funcionando como sujeto en la oración.

R. Cano (1981) también hace alusión a la proximidad entre los complementos direccionales y los objetos indirectos, afirmando que el complemento direccional — sea de 'origen' o de 'destino' - puede aparecer formalmente como objeto indirecto, aunque tal hecho, según él, sólo es posible cuando $\mathrm{cl}$ 'origen' o 'destino' es un sustantivo de rasgo [+ animado], y más específicamente [+ humano]. 
(22) Me trajo un libro.

(23) Le llevé el traje.

(24) Me envió una hermosa carta.

Su planteamiento resulta confuso, pues considerar que el complemento direccional puede aparecer formalmente como un objeto indirecto cuando el 'destino' liene el rasgo [+humano], conlleva un doble análisis, a nuestro parecer, no demasiado justificado; así, si el sustantivo que aparece es [- animado], entonces no tenemos un objeto indirecto, sino un complemento de lugar 'a donde' o 'de donde'.

(25) Llevemos este hecho a sus últimas consecuencias.

$Y$ considera que en estos casos el objeto indirecto parece estar por un complemento de lugar 'a donde', pero que además hay una vaga noción de interés, de implicación de la entidad designada por el objeto indirecto en la acción designada por el verbo, siendo ésta la única idea que queda cuando coexisten un objeto indirecto y un complemento locativo.

(26) Te llevaré el libro a casa.

Estamos de acuerdo con él en cuanto a que lo que lienen en común un objeto indirecto y un complemento locativo, con los verbos de dirección, es que entre la entidad designada por estos complementos y el proceso designado por el verbo existe una relación de mayor implicación, ya que esta entidad se toma como punto de referencia a partir del cual orientar la dirección expresada por el verbo. Así, en todos estos casos, para él, junto al valor direccional de 'destino' u 'origen', sigue presente el valor de 'interés', justificando, de este modo, el que siga definiendo el objeto indirecto como una función semántica, y no como manifestación de varias relaciones (dativo, destino, origen, etc...).

M. Herslund (1988: 67) realiza un análisis de la función dativo en francés y habla de un objeto indirecto de lugar - caracterización que puede resultar interesante para los complementos direccional- pero no entra en especificar si se trata de la misma función o no, sino que únicamente menciona la relación entre el complemento de persona y el complemento de lugar. Considera que ciertos complementos adverbiales tienen el estatuto de actantes, y se cuestiona si no serían puramente objetos indirectos. Piensa que las relaciones fundamentales son las mismas, serían sólamente los detalles de esas relaciones los que cambian en función de la alternancia de lo que él llama O.I.loc (lugar), O.I.dat (Persona) y O.I. neutro ([- humano]). Para él, es de esta diferenciación de la que se derivan los efectos de sentido diferentes que hacen seguir hablando todavía de dos estructuras distintas de un mismo verbo. 
(27) a) Henri váá Rouen

b) Henri y va

(28) a) Il est venu au ministère ce matin

b) Il y cst venu ce matin

(29) a) Cette idće est venue au ministère ce matin

b) Cette idée lui est venue ce matin

Señala que, tanto desde un punto de vista teórico como desde un punto de vista pedagógico, se trataría en ambos casos de un mismo esquema valencial, de la misma construcción de base, aunque la especificación eventual del complemento indirecto entrañaría diferentes lecturas del verbo.Y concluye señalando la unidad de base de estos verbos, pues su objeto indirecto puede manifestarse tanto por un O.I.loc. como por un O.I.dat.

« Mais il n'en reste pas moins que l'important est de souligner l'unité de base de ces verbes: Ieur O.I. peut se manifester aussi bien par un O.I.loc. que par un O.l.dat; le choix de l'un ou de l'autre peut alors avoir des conséquences capitales pour l'interprétation globale de la phrase».

(Herslund, 1988: 67)

Indica que unas de csas consecuencias es que se le asocie un rol más 'activo' al O.Idat: Ia entidad denotada por el constituyente es interpretada como participante en el acontecimiento denotado por el verbo, de una manera o de otra, no se reduce al simple rol de 'lugar' ('destinatario 'o 'beneficiario' son etiquetas que han sido propuestas para designar este aspecto 'activo' del dativo). De aquí procede, para él, la concepción errónea de identificar el dativo con la designación forzosa de un ser animado. Así, resulta evidente que esta interpretación 'activa' o 'participante' del complemento indirecto se impone más fácilmente cuando se trata de un constituyente [tanimado] y [thumano]

F. Osuna (1991: 243-245) aporta una interesante visión de la relación entre estas dos funciones sintácticas desde un punto de vista referencial - no olvidemos que el complemento indirecto es una función que se caracteriza por un alto grado de referencialidad-. Su aportación consiste en que por vez primera se igualan los complementos direccionales independientemente del rasgo [ \pm humano], aunque lo hace desde un punto de vista exclusivamente referencial. Nosotros intentaremos demostrar que esta aglutinación se puede llevar a cabo sin recurrir a exclusivamente a la referencia. Afirma el autor que estos elementos no localizan el proceso, sino el punto de partida o de llegada del proceso, y por ello los considera como determinantes del destino o del origen del proceso.

(30) Hemos ido a Sevilla 
(31) Le entregué las llaves a tu hermano.

(32) Esas palabras salieron de él.

En cuanto a los determinantes del destino del proceso cree que son unidades referenciales acompañadas por las preposiciones a, hasta y hacia y que se caracterizan por tener referencia específica. En su opinión, entre los determinantes del destino se debería incluir el complemento indirecto de los verbos de movimiento, pues la relación que se establece entre los nominales marcados por la preposición a y el proceso designado parece la misma: en ambos casos estaríamos ante nominales marcados por la preposición $a$ y con función referencial específica. La clase de realidad designada en cada caso nos puede servir para distinguir dos tipos de relaciones sintácticas, pues un mismo referente puede aparecer con uno u otro sentido.

(33) Llegamos a la ciudad de Sevilla.

(34) Han regalado una collección de tapices a la ciudad de Sevilla.

(35) Fuimos a la plaza del pueblo.

(36) El Ayuntamiento ha dado un nuevo ambiente a la plaza.

Considera que estos dos sentidos de los determinantes del destino del proceso están bastante relacionados con la clase de proceso designada (movimiento, desplazamiento, dirección). Así, en vez de hablar de funciones diferentes, prefiere hablar de diferentes sentidos de una misma función, o en último extremo, de variantes combinatorias de una misma función sintáctica. En este caso, las variantes combinatorias no se basarían en una diferencia formal, sino en una diferencia semántica, pues los significantes son idénticos en ambos casos, es decir, son determinantes del destino del proceso.

Su propuesta nos parece interesante pues es el único autor que evita realizar un doble análisis más o menos forzado y que, además, nos ofrece una interpretación más ajustada a la relación entre el complemento indirecto y el complemento direccional así como a su comportamiento, considerando que nos encontramos ante variantes combinatorias de una misma función sintáctica, dependiendo, fundamentalmente de si se trata de verbos direccionales - e incluso posicionales - o de otro tipo, pues en un caso se trata de un movimiento local, y en otro de un movimiento abstracto: posesivo, existencial, etc. Luego, son conceptualizaciones distintas, que, además, tendrán diferencias formales.

\section{La dirección desde la semántica cognitiva}

Podría resultar interesante observar cómo se podría explicar desde un punto de vista cognitivo que los complementos de los verbos de dirección puedan ser tanto personas como lugares. 
La dirección es un elemento constitutivo del movimiento y el desplazamiento, y, como éstos son vitales para los humanos en su quehacer cotidiano, obtendrá su correspondiente reflejo en la lengua.

«La indicació de la direcció és molt necessària en el nostre quefer quotidià, ja que és un element fonamental dels moviments i desplaçaments, i aquests sòn vitals per als humans; la direcció no es defineix com una línia en un determinat angle amb l'horitzontalitat del seu origen (como esdevè en matemàtiques, sino que es defineix per mitjans més naturals, dins l'àmbit del que els autors cognitivistes han anomenat una «física näf», ço és, una concepció del món simplificada i ingènua [...] El moviment és una de les activitats humanes més comunes i millor compreses, i per aquesta raó, la llengua en dóna compte amb gran facilitat. Els elements del moviment són un punt de partença, un trayecte i un punt dárribada, $\mathrm{i}$ aqueix trajecte té una direcció».

(Sancho, 1994: 22-23)

J.L. Cifuentes (1989: 38) explica que la disposición espacial de un objeto en un encuentro normalmente es caracterizada en términos de otro objeto, también seleccionado dentro del encuentro, y que por tanto, puede funcionar como objeto de referencia.

Desde la semántica cognitiva se caracteriza la localización espacial como ambitalización, donde una figura y una base son puestas en relación por medio de un sujeto que participa en ello.

«Todo proceso de localización supone una ambitalización, en el sentido de que se necesita una percepción interactiva, funcional y cultural, entre la figura y la base, y esto no sólo presupone un yo que realiza tal tarea sino también un sujeto que se interacciona, logrando un encuentro, con el tipo de ámbito establecido por la figura y la base. Fruto de esta interacción del sujeto con el ámbito formado por la figura y la base son los procesos de localización lingüistica ».

(Cifuentes, 1989: 179)

En cuanto a la dirección, desde el punto de vista de la semántica cognitiva, considera que ésta no puede existir más que para el sujeto que la describe; no hay ninguna dirección en el sentido de que no hay un punto de partida absoluto que pueda, progresivamente, dar un sentido a todas las determinaciones del espacio.

Este autor (Cifuentes, 1989: 32) explica el espacio, desde los principios de la semántica cognitiva, como una propiedad que no es inherente a las cosas y que no se define más que por la relación entre las cosas y los hombres que la perciben.

« Así pues, podemos concluir por el momento que el espacio de la percepción (entendido también como conceptualización), que es con el que opera el espacio lingǘstico, es un espacio relacional y funcional, donde ocupa un lugar fundamental junto con el juego de coordenadas y dimensiones 
la perspectiva usada por el sujeto, al igual que la posible interacción conceptual o cultural - establecida entre los distintos objetos a localizar o entre esos objetos y el enunciador ».

(Cifuentes, 1989: 38)

El término de movimiento introduce un sintagma preposicional (a, de, etc...) y el objeto designado por este sintagma preposicional es uno de los dos términos puestos en relación por la preposición. A este objeto es al que se le ha denominado objeto localizante o base. Más difícil resultaría determinar cuál es el otro término o argumento de la relación designada por el término de movimiento. La solución que parece más apropiada consiste en decir que este segundo término es un objeto del que el objeto localizante especifica el lugar de interacción con el término del movimiento.

L. Talmy (1983: 6-7) ha caracterizado la figura y la base, por lo que atañe a las relaciones espaciales, con los siguientes rasgos: la figura, tiene variables espaciales por ser determinada, es más movible y más pequeña que la base, se concibe más simplemente desde un punto de vista geométrico (como un punto), está más prominente, y, por último, ha aparecido más recientemente que la base en la escena o en la conciencia de los hablantes; por contra, la base actúa como un objeto de referencia con características espaciales conocidas, suele ser inmóvil de una manera más constante que la figura, es concebida con una mayor complejidad geométrica (no como un punto) y más al fondo que la figura, y, por último, aparece más pronto en la memoria o conciencia de los hablantes.

Así, en Juan se dirige al hospital, hospital designaría el objeto localizante o base, y Juan el objeto localizado o figura, es decir, la expresión del término del movimiento o direccional al hospital indicaría la dirección hacia la que se orienta el movimiento o desplazamiento.

(37) Juan se dirige al hospital

figura base

(objeto. localizado) (objeto. localizante)

(lugar que indica el destino de su desplazamiento)

Algo parecido ocurre con los verbos de movimiento que poseen una estructura triactancial, tenga el término de movimiento el rasgo [+ humano] o [Humano].

(38) Juan trajo el libro a la biblioteca

figura base

(39) Juan trajo el libro a su hermano

figura base 
Además, nosotros creemos que este análisis se puede aplicar también a aquellas estructuras en que el término de movimiento o la expresión direccional posee el rasgo [+ humano]:

(40) Juan le llevó un paquete a su hermano

figura base

(obj. Iocalizado) (obj. localizante)

Si nos fijamos en la base nos daremos cuenta de que el objeto localizante posee el rasgo [+ humano], por lo tanto la persona (a su hermano) se ha tomado como referente para indicar el destino de su desplazamiento. Creemos que una entidad con el rasgo [+ humano], es decir, una persona, puede perfectamente tomarse como base o punto de referencia para orientar la dirección designada por el proceso verbal, ya que las personas cumplen todos los rasgos que L. Talmy considera que caracterizan a la base del movimiento. En el ejemplo anterior (Juan le entregó un paquete a su hermano) su hermano tiene una referencia espacial o localización conocida por los interlocutores, su hermano -que funciona como base - es más grande que la figura (un paquete), su hermano es concebido como menos inminente o más al fondo que la figura (un paquete), la base, su hermano, ha aparecido antes que la figura, un paquete, en la memoria o conciencia de los hablantes — pues de los participantes que intervienen en el proceso descrito un paquete es la última entidad que se ha presentado en el entorno compartido por los interlocutores-, y por último, aunque su hermano no es esencialmente inmóvil, se toma como base al considerar esta entidad como un punto, cocibiéndola como algo inmóvil o estático durante la realización del proceso designado.

Los verbos de desplazamiento implican una localización de forma explícita, requieren una obligatoriedad sintagmática del objeto localizante tanto con personas como con no personas, es decir, el objeto localizante necesita obligatoriamente de una explicitación cotextual sintagmática.

Los complementos de los verbos de dirección pueden tener el rasgo [+humano] o [-humano], identificándose entonces con las funciones complemento indirecto y complemento preposicional o suplemento respectivamente, por lo que los gramáticos suelen proponer un doble análisis que, desde nuestro punto de vista, oculta la igualdad funcional entre estos dos complementos. En realidad, nos encontramos ante la conversión lugar-objeto. Los verbos de dirección describen el camino que sigue la figura, para indicar este camino se necesita un punto de referencia a partir del cual orientar ese trayecto; pues bien este punto de referencia puede ser una entidad que tenga tanto el rasgo [+humano] como [humano]. Lo que importa es tener una entidad que sirva de base, de objeto localizante del destino del desplazamiento. 
Esta entidad suele ser un objeto (la esquina, la farola) que se conceptualiza como un lugar (conversión lugar-objeto), pero también se puede conceptualizar a una persona como un lugar, pues puede servir de punto de referencia a través del cual orientar la dirección del movimiento descrita por el verbo.

\section{Caracterización del término de dirección}

Consideramos que el complemento indirecto y el complemento direccional ${ }^{5}$ no se comportan como dos funciones diferentes, sino que serían más bien distintos sentidos de una misma función o variantes combinatorias de una misma función sintáctica (término de dirección) caracterizada por una serie de rasgos sintáctico-semánticos necesarios (presenta obligatoriedad sintagmática o explicitación cotextual, y sirve de punto de referencia o base para el movimiento), y que sólo se diferenciarían en que el complemento direccional aparece con verbos locales expresando la idea de origen o destino, mientras que el complemento indirecto aparece con verbos no locales, expresando la idea de 'afección'. Profundizando en sus diferencias observamos que se oponen en la manera o modo de conceptualizar el proceso del movimiento, provocado, fundamentalmente, por la distinta cualidad del movimiento que se da en uno y en otro, pues mientras el complemento indirecto presenta un movimiento abstracto, el complemento direccional muestra un movimiento físico, y por tanto, espacial. Este distinto carácter o cualidad del movimiento, bien físico bien abstracto, es el que motiva una conceptualización distinta de la transferencia que se efectúa. El complemento direccional expresa idea de 'destino' u 'origen', según que el movimiento se considere desde el punto de llegada o desde el punto de partida, determinando el origen o el destino del proceso, mientras que el complemento indirecto expresa 'afección'; éste caracteriza e identifica a la entidad descrita como humana y definida, mientras que el complemento direccional la caracteriza como una cosa; en el complemento indirecto prevalece la descripción del participante en vez de la preposición, como ocurre en el complemento direccional; el complemento indirecto define un proceso esquemático de asimetría transitiva - la fuerza que el agente provoca a través del proceso va a parar casi en su totalidad al segundo complemento- en vez de definir un cambio espacial dirigido, como sucede en el complemento direccional; describe el complemento indirecto un proceso en vez de designar una relación atemporal, como ocurre en el complemento direccional; y finalmente, el complemento direccional tendría un carácter relacional más que nominal, como sucede en el complemento indirecto (Cfr. Langacker, 1994). Por lo tanto, sería

5 Siempre nos referimos al llamado complemento infirecto con verbos de lugar o de desplazamiento, no al complemento indirecto en general. 
esta distinta conceptualización de la transferencia designada en el proceso la que provocaría una diferenciación sintáctica: complemento indirecto vs. complemento direccional.

Prácticamente, todos los problemas que nos encontramos cuando queremos distinguir el objeto indirecto del complemento direccional provienen del hecho de establecer criterios demasiado rígidos y taxativos para intentar separar estas dos categorías, cuando, sin embargo, entre ellas no hay más que una diferenciación gradual. De este modo, entre un extremo y otro habría casos de complementos direccionales puros y de complementos indirectos puros, y en medio habría diversos casos intermedios más o menos próximos a uno o a otro (Sancho, 1994: 101). Por lo tanto, tendríamos una gradación desde los complementos esencialmente «direccionales» hasta los esencialmente «objeto indirecto» (Juan se acercó hasta la puerta, Juan le dió una bofetada a su amigo).

Así los complementos indirectos pertenecen a un nivel abstracto en el que, aunque haya un movimiento, éste se da en un dominio que no es propiamente espacial. En estos casos no podemos afirmar, de una forma tajante, que haya efectivamente un traslado de un lugar a otro, o al menos no se conceptualizaría este movimiento. Esto se explicaría por el hecho de que «el movimiento abstracto se construye según el espacio, y por eso hablamos de movimiento» (Sancho,1994:103). Siendo esto así, parece lógico pensar que cuanto más presente esté la idea de un verdadero movimiento (un movimiento físico) menos «indirecto» es el complemento indirecto, hasta poder incluso dejar de serlo. Esto se puede ver claramente en los verbos de tres argumentos que normalmente subcategorizan un nombre [-animado] (locativo), analizándose entonces como complemento direccional. Sin embargo, también pueden aparecer con un nombre [tanimado], y entonces sería un objeto indirecto pronominalizable por lef les.

(41) a) Juan envió una carta a su hermano (c. indirecto)

b) Juan envió una carta a Francia. (c. indirecto)

En español los verbos direccionales, por regla general, admiten con bastante naturalidad tanto el objeto indirecto como el complemento direccional sin existir ninguna tendencia o preferencia hacia uno en concreto como para considerar que uno es más relevante (más frecuente) que otro. Por lo tanto, no podemos preveer con ninguna certeza si el término de dirección será una persona o un lugar, pues lo relevante de estos verbos es que, aunque etimológicamente sean espaciales, están perfectamente configurados para tener como punto de referencia - a partir del cual orientar la dirección- tanto un lugar como una persona. 


\section{Dativos correferenciales.}

$M^{a}$ V.Vázquez (1989: 146) nos hace observar que, en las secuencias donde aparece un sintagma preposicional (a ella/ a la pared), el sentido básico es locativo, mientras que está ausente la noción de afección e implicación que se da en la situación descrita por las secuencias en que aparece el pronombre átono:

(42) Juan se le acercó

Pr. átono [+ humano]......'afección', 'implicación'

(43) Juan se acercó a ella

S. Preposicional [+ humano] ....'dirección'

Creemos que resulta bastante forzada la oposición de sentido 'afección' $v s$. 'dirección' basándose en la diferencia formal pronombre átono vs. sintagma preposicional, pues en ambos casos desempeñan la misma función sintáctica, e incluso poseen el rasgo [+ humano]. Consideramos que en ambos nos encontramos ante un sentido o valor de 'dirección', y esto es así porque la persona (clítico dativo o sintagma preposicional) es la «entidad afectada» al tomarse como punto de referencia a través del cual orientar la dirección del movimiento expresado por el verbo. Luego es este rasgo general de 'afección' - que posee el complemento indirecto- el que permite que estos constituyentes puedan adquirir un valor añadido de 'dirección' (dativo de dirección), que vendrá dado fundamentalmente por el proceso que designe el verbo.

Considera $\mathrm{M}^{\mathrm{a}} \mathrm{V}$. Vázquez que el pronombre átono (le, les) no puede aplicarse sino a verdaderas personas, o por lo menos, a seres animados o personificados.

"Se dice deseando conocer a aquellos hombres me les acerqué o me acerqué a ellos; pero no creo que pueda decirse con igual propiedad: Quise gozar de la sombra de aquellos árboles y me les acerqué. Sería mucho mejor, a mi parecer: me acerqué a ellos.»

(Vázquez, 1989: 146)

Creemos que identificar el clítico de dativo con personas es sólo una tendencia de la lengua, debido fundamentalmente al grado de prototipicidad de la función complemento indirecto, pues nos podemos encontrar en algunos casos con clíticos de dativo que son correferenciales a un objeto indirecto [animado], aunque no sea lo más frecuente.

(44) Juan le dió cuerda al reloj.

6 Nos parece que me les acerqué es una estructura que resulta algo forzada. 
En secuencias donde aparezca un predicado como acercarse propone un doble análisis, pues para ella nos encontraríamos ante dos esquemas sintácticos diferentes dependiendo de si el complemento está representado por un átono dativo (función complemento indirecto) o un sintagma preposicional (función complemento adverbial -regido o suplemento-).

(45) Juan se le acercó (complemento indirecto)

(46) Juan se acercó a su hermana (C. Adverbial)

Nos parece que este doble análisis no está justificado, pues tienen un mismo funcionamiento en la secuencia (el pronombre le puede sustituir al sintagma preposicional a su hermana), y, además, hacen referencia a la misma realidad extralingüística; la única diferencia reside en la forma de ambos, en un caso se trata de un pronombre átono y en otro de un sintagma preposicional. Por tanto, siguiendo su doble análisis no se podrían explicar las estructuras donde aparece el clítico correferencial, es decir, estructuras donde aparece el sintagma preposicional en alternancia con el pronombre dativo átono lefles, o estructuras en las que la presencia de éste es obligatoria pra que la oración resulte gramatical.

(47) El fiscal le envió una carta al juez.

(48) El dentista le arrancó un diente a Luis.

R. Cano (1981:91) nos explica que con los verbos de movimiento cuando el 'destino' es un ser humano, puede aparecer también como dativo pronominal, uniéndose entonces este valor de destino con los otros valores que suelen estar presentes en la relación sintáctica verbo-objeto indirecto: el de «daño»o «provecho», y el «posesivo»?

(49) Me tiró una piedra.

(50) Le arrojaron un cubo de agua.

\subsection{Reduplicación e iconicidad}

V. Demonte (1994: 69-73) es la primera en estudiar la relación entre los verbos de movimiento que describen el cambio de localización de un objeto de las construcciones de clítico dativo, asociándolo con la noción de causa implicada en estas construcciones. Se pregunta si la alternancia clítico/ausencia de

7 Es lógico, si la persona es la base término del movimiento, y la figura es una «piedra», lógicamente, ésta sólo puede ocasionar daño, si es un «pastel», puede ser daño si es arrojado cion intención, o provecho. Es decir, no se trata sino de meras anécdotas dependientes de la configuración pragnática del esquema espacial. 
clítico en las construcciones de cambios de ubicación constituye un caso de libre variación, o si conlleva cambios en la interpretación de estas expresiones. Cree que hasta ahora los que han estudiado la reduplicación de los objetos indirectos mediante el clítico dativo dan por supuesto que esta alternancia es totalmente libre. Pero, sin embargo, parece ser que para muchos hablantes y probablemente para muchos dialectos la presencia del clítico es obligatoria.

Aun así, en español parece que resulta muy difícil concebir que pudiera haber variación de significado entre la construcción con clítico o sin él en los verbos de transferencia, es decir, el hablante no siente que entre Entregué la documentación al secretario y le entregué la documentación al secretario haya una diferencia semántica clara. Pero Demonte afirma que si observamos qué sucede con otras formas semejantes de cambio de ubicación, podremos entonces configurar la i lea de que esas dos estructuras no son completamente equivalentes.

(53) Le extrajo las piedras a la pulsera.

(52) Le quitó las manchas a la tela.

(53) Le acercó el libro a su hermano.

Para comprobar esto nos propone reflexionar sobre los siguientes pares de oraciones:

(54) a) Puso el tornillo en la cerradura.

a') Le puso el tornillo a la cerradura

b) Puso los platos en la mesa.

b') * Le puso los platos a la mesa

(55) a) Arrancó una hoja del árbol.

a') Le arrancó una hoja al árbol

b) Quitó/retiró los platos de la mesa.

b') *Le quitó/retiró los platos a la mesa (cf. Le quitó el polvo a la mesa).

(56) a) Devolvió las llaves a su antiguo amante.

a) Le devolvió las llaves a su antiguo amante.

b) Devolvió los libros a la biblioteca.

b') *le devolvió los libros a la biblioteca.

Explica los contrastes de $^{8}(54),(55)$ y (56) señalando que, frente a la construcción sin clítico - que describía tan sólo el cambio de ubicación de un objeto por medio de la acción de un agente- la que contiene el pronombre átono implica que la Locación o Meta tienen una relación muy «estrecha» con el

* Teniendo en cuenta que en el primer grupo hay movimiento, en el segundo cambio de posición y en el tercero transferencia pero no localización. 
objeto desplazado. Según explica, esta relación puede ser de afectación material de la Meta: un ser animado que se interpretará como poseedor material del objeto movido (correspondería al llamado dativo posesivo por la gramática tradicional).

(57) a) Devolvió el coche a su padre.

a') Le devolvió el coche a su padre.

o de afectación-posesión inintencionada en cuanto un todo posee a sus partes (árbol/hojas; cerradura/tornillos; relaciones metonímicas).

(58) Le arrancó una hoja al árbol.

(59) Le puso el tornillo a la cerradura.

V. Demonte nos señala otro elemento que favorece la presencia del clítico correferencial, para ello, nos propone reflexionar sobre los siguientes ejemplos:

(60) a) Juan le quitó/limpió la mancha a la tela

b) *Juan le rascó/rasguñó la mancha a la tela (Cf. Juan rascól rasguñó la mancha de la tela).

Considera que la diferencia de gramaticalidad entre ambos está determinada por la presencia del clítico dativo en (60b), pues estos verbos rechazan el dativo porque la acción descrita implica un tipo de contacto en el que no hay relación estrecha entre el locatum y el afectado por la acción verbal. Así, en los verbos de (60a) la mancha que se quita o limpia está integrada a la tela, en la serie de (60b) la mancha ha de ser más externa.

«El hecho de que el clítico exprese esa relación entre la Meta y el Tema lleva consigo el que estas estructuras se interpreten en ocasiones como asociadoras de una «presuposición de existencia» de la Meta o Locación afectada. La presuposición de existencia se sigue de la afección de esas entidades, por eso a una pregunta como ¿Qué harás con el coche? es perfectamente posible contestar Lo venderé a quien me dé más (en el cual el clítico dativo tiende a evitarse). A la pregunta paralela ¿QQué hiciste con el coche?, que remite, en cambio, a acción concluida, resulta más adecuado responderla con una estructura en la que el clítico esté presente: se lo vendí a Pedro.»

(Demonte: 1994: 71).

Concluye afirmando que el clítico dativo viene a ser agramatical cuando el sujeto es inanimado o no es el Agente primitivo.

(63) a) La señora/el superglú pegó el asa en la tetera.

b) la señora le pegó el asa a la tetera.

c) *El superglú le pegó el asa a la tetera. 
(62) a) El profesor/?el libro describió el español a los extranjeros.

b) El profesor les describió muy bien el español a los extranjeros.

c) ?El libro les describió muy bien el español a extranjeros.

Pero no quiere asignar estos contrastes a la carencia o presencia de un rasgo animado, puesto que no se ha visto todavía que este rasgo desempeñe un papel directo en los procesos léxico-semánticos. Además, añade una prueba que confirma que no se trata de una cuestión de animacidad porque cuando un objeto mecánico es agente primigenio la oración con le es perfectamente correcta.

(63) La grúa le arrancó el parachoques al coche de Luis.

Creemos que, si entre la designación del objeto indirecto (al coche) y la de su adyacente nominal (de Luis) existe una relación de parte-todo, respectivamente, entonces, éste adquiere un sentido de 'pertenencia' o 'poscsión', determinado por la relación lógica señalada. Todos estos objetos indirectos son susceptibles de ser transformados en complementos del nombre mediante la sustitución de a por de (Morera, 1988: 521). De este modo, mientras que en el primer caso se pone el énfasis sobre el todo como persona o cosa dañada o beneficiada por la acción verbal, en el segundo, se pone el énfasis sobre la parte, y el todo se presenta como un mero determinante del objeto indirecto. En estos casos, existe una mayor relación entre estos dos elementos, pues hay implícita una relación de «posesión inalienable». Así, desde un punto de vista cognitivo sería un proceso metonímico por el que se le concederían al objeto indirecto (coche) las características de la persona (Luis), porque es algo suyo.

Resulta evidente que en la mayoría de casos la alternancia presencia/ausencia de clítico en las construcciones direccionales no constituye un caso de libre variación, sino que conlleva cambios de interpretación semántica en esas expresiones, a pesar de lo difícil que en un primer momento pudiera resultar percibir de forma clara esta variación.

(64) a) Juan llevó el sobre a la secretaria.

b) Juan le llevó el sobre a la secretaria.

La variación semántica entre estas dos estructuras estriba en que, cuando no aparece el clítico, se describe únicamente el movimiento de un objeto por medio de la acción de un agente, mientras que cuando aparece el clítico queda implicado que la base (Locación o Meta) mantiene una relación muy estrecha con la figura (objeto desplazado).

La iconicidad nos permitirá explicar la estructura del clítico (pronombre átono dativo) correferencial. Haiman indica la existencia de cicrtos aspectos 
lingüísticos que reflejan en su forma de estructura gramatical el significado de sus referentes. Señala dos clases de iconicidad lingüística, el isomorfismo y motivación; éste último tipo de iconicidad es el que más nos interesa:

« $[\ldots]$ the estructure of langage reflects some aspect of the structure of reality ".

(Haiman, 1980: 517; 1985: 11)

La reduplicación del sintagma preposicional en función de un hipotético complemento indirecto por un pronombre dativo átono (le/les) es muestra del carácter icónico del clítico correferencial. Las estructuras direccionales que permiten la reduplicación del complemento indirecto por le/les están marcando una mayor y más estrecha relación de afectación entre la figura y la base. Pues bien, esta relación de mayor grado de afectación entre estas dos entidades se va a reflejar icónicamente en la lengua mediante la repetición o reduplicación por el clítico le/les de la entidad más afectada; es decir, a mayor afectación existente entre estos dos elementos (figura y base) mayor intensidad e insistencia se dará sobre esta entidad (base, tercer participante) obteniendo un reflejo icónico en la lengua mediante más formas linguísticas: repetición, reduplicación.

La iconicidad lingüística nos hace patente que la organización gramatical de las oraciones experimenta directamente las funciones semánticas que representan (Langacker, 1992:191). Con la iconicidad lingüística sólo pretendemos destacar cómo este fenómeno lingüístico se ajusta a nuestra caracterización del clítico correferencial.

\subsection{Propuesta prototípica del dativo átono}

Proponemos que el clítico correferencial posee una organización prototípica caracterizada por una serie determinada de rasgos (humano, determinado o definido, participante más comprometido o de mayor afección, causatividad o presencia de un agente primario, y marcador de topicalidad) que favorecen su aparición, sin ser necesario que se den todos simultáneamente.

Si el complemento indirecto o la base de un complemento de lugar es una persona, y además, determinada y definida, entonces es más fácil que aparezca un clítico correferencial de dativo. Si a esto se le añade que este participante se encuentra muy afectado por el proceso verbal o guarda una relación de implicación con el objeto directo («parte-todo», «posesión»), entonces favorece más todavía su aparición, e incluso la exige para que la oración sea gramatical y aceptable. El factor de la topicalidad también influye en la aparición de los clíticos correferenciales, sin embargo, nos resulta difícil aludir a él porque se da en la enunciación, en el discurso. 
Por ejemplo, no todos los clíticos correferenciales de dativo tienen un mismo comportamiento lingüístico, existen diferencias entre ellos, aunque todos realizan el concepto funcional que se pretende describir.

(65) a) Antonio le arrojó una piedra a su amigo

$\begin{array}{cc}\text { [Agente] } & {[+ \text { humano }]} \\ & {[+ \text { def./det. }]} \\ & {[+ \text { participante afectado }]}\end{array}$

b) El dentista le arrancó un diente a Luis

[Agente]

[+humano]
[+ def./det.]
[+ participante ajectado]
[+ implicación, posesión]

En ambas oraciones aparece el clítico correferencial de dativo (le), y parecen poseer las dos los mismos rasgos; sin embargo, aunque en los dos casos cumplen la misma función, no tienen un mismo comportamiento lingüístico. En el primer ejemplo (65a) el clítico es opcional, es decir, el verbo arrojar admite la alternancia presencia/ ausencia del clítico correferencial; sin él describe tan sólo el cambio de ubicación de un objeto por medio de la acción de un agente, con el pronombre átono implica que la Locación o Meta mantiene una relación muy estrecha con el objeto desplazado. Esta relación de mayor implicación se manifiesta de forma icónica en la lengua mediante la reduplicación del complemento indirecto.

(66) a) Antonio le arrojó una piedra a su amigo.

b) Antonio arrojó una piedra a su amigo.

En (66b) la aparición del clítico es obligatoria; el verbo arrancar exige la presencia del clítico correferencial, de esta forma implica que la estrecha relación que existe entre la Locación o Meta y el objeto desplazado es del tipo "parte-todo», "posesión» o «poseedor material», y «presuposición de existencia»(Cfr. solidaridad léxica en Coseriu, 1977: 48).

(67) a) El dentista le arrancó un diente a Luis.

b) El dentista arrancó un diente a Luis.

Luis es el poseedor de los dientes; los dientes forman parte del cuerpo (todo) de Luis; los dientes implican la existencia de una entidad animada [+ mamífero], es decir, entre ellos se da una solidaridad léxica. En estos casos el hipotético dativo de dirección está muy próximo al dativo posesivo tal como lo 
caracteriza D.Domitrescu (1988) y también de lo que se ha denominado como posesión inalienable, caracterizada como una situación en que A posee a B en una forma tal que $B$ es impensable en la ausencia de $A$, o sea, hasta el punto de quo si $B$ (el objeto poscído) está presente en el discurso, $A$ (el poseedor) debe estarlo también de manera obligatoria. Y si algo le sucede al objeto poseído B, el poseedor A resulta afectado necesariamente. Hay nombres que son inherentemente relacionales, como las partes del cuerpo, las prendas de vestir, los nombres de parentesco, las relaciones sociales, y las facultades físicas o intelectuales, frente a otros nombres que no lo son. Esta estructura la encontramos con verbos que pertenecen a la clase semántica de la 'extracción material', 'subtraccion' o 'desposesión': erradicar, sustraer, extirpar, arrancar, ctc.

Consideramos que el dativo de dirección debe ser explicado tomando como punto de partida esencial la implicación de los participantes en la situación discursiva y el lugar ocupados por los mismos en una jerarquía de topicalidad.

Pero que quede claro que el pronombre átono de dativo es un problema morfológico de correferencialidad, en el caso de estructuras de desplazamiento físico, sólo posible cuando la base es un persona, y que desempeña, semánticamente, un ejemplo de iconicidad sintáctica.

\section{Conclusiones}

Crecmos que existe una cierta similitud, en numerosas lenguas no emparentadas, entre el complemento direccional y el indirecto, es decir, entre las estructuras locativas y dativas que se dan en la construcción de «doble objeto» con los verbos de dirección; por lo que parece que nos encontramos ante un problema de conceptualización, en el que lo que cambia es el modo de conceptualizar un mismo acontecimiento, como movimiento abstracto o como movimiento local. la diadema a su compañera, Juan le puso la diadema a su compañera).

Ahora bien, lo que proponemos es que el considerado «complemento indirecto», cuando aparece con los verbos de dirección - nuestro dativo de dirección-, funciona como índice locativo, en concreto expresa el término del movimiento, es decir, la entidad humana a que se refiere el complemento indirecto se concibe, entonces, como referencia espacial en cuya órbita se situaba, antes del movimiento, la otra entidad que aparece funcionando como sujeto en la oración. Lo que tienen en común un objeto indirecto y un complemento locativo con los verbos de dirección es que entre la entidad designada por estos complementos y el proceso designado por el verbo existe una relación de mayor implicación, por cuanto esta entidad se toma como punto de referencia a partir del cual orientar la dirección expresada por el verbo.

En realidad, nos encontramos ante la conversión lugar-objeto. Los verbos de dirección describen el camino que sigue la figura, para indicar este camino se 
necesita de un punto de referencia a partir del cual orientar ese trayecto; pues bien este punto de referencia puede ser una entidad que tenga tanto el rasgo [+humano] como [-humano]; lo que importa es tener una entidad que sirva de base, de objeto localizante del destino del desplazamiento. Esta entidad suele ser un objeto (la esquina, la farola) que se conceptualiza como un lugar (conversión lugar-objeto), pero también se puede conceptualizar a una persona como un lugar, pues puede servir de punto de referencia a través del cual orientar la dirección del movimiento descrita por el verbo.

De esta forma, consideramos que el complemento indirecto y el complemento direccional son distintos sentidos de una misma función o variantes combinatorias de una misma función sintáctica (término de dirección) caracterizada por una serie de rasgos sintáctico-semánticos necesarios (presenta obligatoriedad sintagmática, y sirve de punto de referencia para el movimiento) y que sólo se diferencian en la clase semántica de los verbos con los que aparecen (verbos locales vs. no locales), provocando así una distinta conceptualización de la transferencia designada en el proceso, que es la que motivaría una diferenciación sintáctica: complemento indirecto ys. complemento direccional.

Analizando los verbos de dirección del español, hemos podido deducir que la complementariedad entre el dativo y el término del movimiento directivo no parece corresponder a la oposición [tanimado] vs. [- animado], como se ha considerado normalmente, sino que está condicionada por la naturaleza de la relación entre los argumentos correspondientes en la frase. Así, muchos verbos seleccionan un tipo de lugar específico, y por consiguiente, no pueden seleccionar el lugar que ocupa una persona. Por ejemplo, algunos verbos seleccionan un lugar muy amplio y extenso, configurado como una nación, como emigrar, deportar, expatriar, inmigrar, extraditar, exportar, etc. Éstos únicamente pueden aparecer con persona mediante un proceso metonímico por el que se selecciona el lugar que ocupan estas personas (Los agricultores exportaron naranjas a Francia/a los franceses). Otros verbos el lugar que seleccionan es agua, como arribar, zarpar, bucear, bolinear, etc., o aire, como, volar, planear, aerotransportar, etc.; con estos verbos, cuando aparece una persona, es también porque se toma metafóricamente el lugar que ocupa la persona como origen o destino del movimiento.

Otro caso interesante es el de los verbos que seleccionan la dimensión interior (entrar, adentrarse, ahondar), pues éstos rara vez pueden seleccionar una persona como término del movimiento, ya que resulta difícil conceptualizar a una persona como una dimensión interior; pero si esto ocurre es siempre metafóricamente, por ejemplo, en Le entraron unos dolores a su padre, en el que los dolores no entran en el cuerpo sino sólo metafóricamente.

Resulta interesante observar cómo algunos verbos cambian de significado según conceptualicen el término del movimiento como una persona o como un 
lugar; por ejemplo, asistir, si conceptualiza un lugar, Antonio asistió a la reunión, tiene el significado de 'estar presente', mientras que si conceptualiza el término del movimiento como un lugar, entonces tiene el significado de 'ayudar'.

Pero, sin duda alguna, el caso más interesante es el de los verbos que seleccionan el lugar unde o de donde, pues la preposición de entra en competencia con $a$, preposición que se prefiere frecuentemente a de en estos casos. A primera vista, la conmutabilidad de ambas preposiciones está condicionada por la oposición [tanimado] vs. [-animado], es decir, un S.N. [-animado] que se refiera al origen de un movimiento no admitiría sino de, pero esta oposición no resulta pertinente. La aparición de a delante de un S.N. [-animado] está ligada a una relación de pertenencia entre objeto directo y objeto indirecto, y es por ello que, en estos casos, el S.P. de origen permita tanto una interpretación espacial como una interpretación posesiva (el jardinero le arrancó una rama al árbol)

También observamos que de reaparece con mayor frecuencia, cuando el verbo, a pesar de su carácter agentivo implica una acción cuyo agente es coreferencial con el origen del proceso descrito. Creemos que esto explicaría los casos en que alterna la preposición $a$ y de en la determinación del origen del proceso, cuando la entidad que funciona como origen posee el rasgo [+animado], como ocurre con el verbo huir (El ladrón huía dela los policías), por lo que parece que nos encontramos ante dos conceptualizaciones de una misma situación, una causativa y otra directiva. La aparición de la preposición a se debe quizás a la presencia del sólo rasgo [+agentivo], apoyada por la relación de posesión, pues ya conocemos el uso frecuente del objeto indirecto en vez de un complemento adnominal, si este mantiene con el objeto directo una relación de posesión inalienable.

En un primer momento, pensábamos que el dativo de dirección podía aparecer alternando con la presencia o ausencia del clítico correferencial de dativo, pero esta alternancia no es totalmente libre, pues con algunos verbos de dirección - los que expresan 'extracción material' o 'substración' - la presencia del clítico parece obligatoria.

La variación semántica entre estas dos estructuras estriba en que en la que no aparece el clítico describe únicamente el movimiento de un objeto por medio de la acción de un agente, mientras que en la que aparece el clítico implica que la base (Iocalización o meta) mantiene una relación muy estrecha con la figura (objeto desplazado).

Pensamos que la iconicidad nos permite explicar la estructura del clítico (pronombre átono dativo) correferencial; la reduplicación del sintagma preposicional en función de un hipotético complemento indirecto por un pronombre dativo átono (le/les) es muestra del carácter icónico del clítico correferencial. Las estructuras direccionales que permiten la reduplicación del complemento indirecto por le/les están marcando una mayor y más estrecha 
relación de afectación entre la figura y la base. Pues bien, esta relación de mayor grado de afectación entre estas dos entidades se va a reflejar icónicamente en la lengua mediante la repetición o reduplicación por el clítico lefles de la entidad más afectada; es decir, a mayor afectación existente entre estos dos elementos (figura y base) mayor intensidad e insistencia se dará sobre esta entidad (base, tercer participante) obteniendo un reflejo icónico en la lengua mediante más formas linguísticas: repetición, reduplicación.

Por ello, proponemos el clítico correferencial como una categoría prototípica caracterizada por una serie determinada de rasgos (Humano, determinado o definido, participante más comprometido o de mayor afección, y marcador de topicalidad) que favorecen su aparición, sin ser necesario que se den todos simultáneamente.

Así pues, en los verbos de dirección -que expresan 'extracción material' o 'substración' - la presencia del clítico es obligatoria (?el dentista arrancó el diente a Luis/El dentista le arrancó el diente a Luis); el verbo arrancar exige la presencia del clítico correferencial, de esta forma implica que la estrecha relación que existe entre la localización o la meta y el objeto desplazado es del tipo «parte-todo», «posesión» o «poseedor material», y «presuposición de existencia» (El dentista le arrancó un diente a Luis, *El dentista arrancó un diente a Luis)

\section{Referencias bibliográficas.}

CANO AGUILAR, R. (1981): Estructuras sintácticas transitivas en el español actual, Gredos, Madrid.

CIFUENTES HONRUBIA, J.L. (1988-89): «Sobre las construcciones locales en español», ELUA, 5, pp. 145-181.

CIFUENTES HONRUBIA, J.L (1989): Lengua y espacio. Introducción al problema de la deíxis en español, Universidad de Alicante, Alicante.

CIFUENTES HONRUBIA, J.L.(1994): Gramática Cognitiva. Fundamentos críticos, Eudema, Madrid.

COSERIU, E. (1977): El hombre y su lenguaje, Gredos, Madrid.

DEMONTE, V. (1994): «La semántica de los verbos de «cambio»», Cuadernos de Lingüística del I. U. Ortega y Gasset, 1994, vol. 2, pp. 55-82.

HAIMAN, J. (1980): «The iconicity of grammar: isomorphism and motivation», Language, 56-3, 1970, pp. 595-600.

HAIMAN, J. (1985): Natural syntax, Iconicity and erosion, Cambridge University Press, Cambridge.

HERSLUND, M. (1988): Le datif en française, Éditions Peeters, Louvain-Paris. LANGACKER, R. W. (1987): Foundations of Cognitive Grammar, I, Standford University Press, stanford.

LANGACKER, R. W. (1991): Fondations of Cognitive Grammar, 2. Descriptive 
Applications, Standford University Press, Standford.

LANGACKER, R. W. (1994): «A Note of Spanish Personal A», mecanografiado.

LYONS J. (1968): Introducción en la lingüística teórica, Teide, Barcelona.

MORERA PÉREZ, M. (1988): Estructura semántica del sistema preposicional del español moderno y sus campos de uso, Servicio de Publicaciones del Excmo. Cabildo Insular de Fuerteventura, Santa Cruz de Tenerife.

OSUNA GARCÍA, F. (1991): Las funciones referenciales en el castellano como bases de una gramática constructiva, Universidad de Granada, Granada.

REAL ACADEMIA ESPAÑOLA (1994): Gramática de la lengua española, edición de E. Alarcos, Espasa-Calpe, Madid.

ROEGIEST, E. (1983): «Funciones sintagmáticas de las preposiciones españolas 'a' y 'de'. Gramática casual y gramática relacional», Lingüística Española Actual, 5/1, 1983, pp. 29-56.

SANCHO CREMADES, P. (1994): Les preposicions en catalá, Universitat de València, Valencia.

TALMY, L. (1983): «How language structures space», Institute of Cognitive Studies, Bcrkeley.

VÁZQUEZ ROZAS, Mª V. (1989): El complemento indirecto en español, Tesis Doctoral, Universidad de Santiago de Compostela, Santiago de Compostela. 